Draft. Comments Welcome.

December 28, 2005

\title{
From Harm to Robustness: A Principled Approach to Vice Regulation
}

\author{
Jim Leitzel \\ University of Chicago \\ C Box 55 \\ 5845 S. Ellis Ave \\ Chicago, IL 60627 USA \\ j-leitzel@uchicago.edu
}

\begin{abstract}
John Stuart Mill's harm principle maintains that adult behavior cannot justifiably be subject to social coercion unless the behavior involves harm or a significant risk of harm to non-consenting others. The absence of harms to others, however, is one of the distinguishing features of many manifestations of "vices" such as the consumption of alcohol, nicotine, recreational drugs, prostitution, pornography, and gambling. It is therefore with respect to vice policy that the harm principle tends to be most constraining, and some current vice controls, including prohibitions on prostitution and drug possession, violate Mill's precept. In the vice arena, we seem to be willing to accept social interference with what Mill termed "self-regarding" behavior. Does consistency then imply that any popular social intervention into private affairs is justifiable, that the government has just as much right to outlaw skateboarding, or shag carpets, or spicy foods, as it does to outlaw drugs? In this paper I argue that advances in neuroscience and behavioral economics offer strong evidence that vices and other potentially addictive goods or activities frequently involve less-than-rational choices, and hence are exempt from the full force of the harm principle. As an alternative guide to vice policy, and following some direction from Mill, I propose the "robustness principle": public policy towards addictive or vicious activities engaged in by adults should be robust with respect to departures from full rationality. That is, policies should work pretty well if everyone is completely rational, and policies should work pretty well even if many people are occasionally (or frequently) irrational in their vice-related choices. The harm and robustness principles cohere in many ways, but the robustness principle offers more scope for policies that try to direct people "for their own good," without opening the door to tyrannical inroads upon self-regarding behavior.
\end{abstract}

I would like to thank Nicole Eitmann, Mark Kleiman, Andrew Koppleman, Peter Reuter, Larry Alexander, and participants at a workshop at the University of Chicago for helpful comments. 


\title{
From Harm to Robustness: A Principled Approach to Vice Regulation
}

\author{
Jim Leitzel
}

\section{Introduction}

Most nations tax alcoholic beverages more highly than other goods, and all nations ban sales of some drugs. In Turkmenistan, opera is proscribed; in Uzbekistan, billiards are banned. ${ }^{1}$ Are these regulations justifiable? To what extent can a government legitimately regulate or prohibit goods or activities that it disfavors?

In his 1859 essay On Liberty, John Stuart Mill introduced a principle by which such questions should be judged. Mill's approach does not provide a recipe for desirable policies; rather, Mill's principle acts as a filter through which policies that unjustifiably intrude upon individual liberty can be screened out. A regulation that meets Mill's criterion is not necessarily a good idea, but, if you accept his principle, a regulation that fails the challenge represents an impermissible infringement upon personal freedom.

The filter that John Stuart Mill offered has achieved renown as the "harm principle": ${ }^{2}$

...the only purpose for which power can be rightfully exercised over any member of a civilised community, against his will, is to prevent harm to others. His own good, either physical or moral, is not a sufficient warrant.

Social coercion (not just governmental coercion) exercised over you for your own wellbeing, in the absence of "harm to others," is a violation of your individual liberty. Mill quickly offers the necessary child-excluding qualification, "that this doctrine is meant to apply only to human beings in the maturity of their faculties."3 
The harm principle tends to be particularly potent when it is applied to vices such as the consumption of alcohol, tobacco, and other drugs; wagering; and prostitution and pornography. The direct ill effects of vice generally are borne by the person who engages in the vice. A person who drinks too much suffers the hangover himself. A person who gambles too much loses money that is his or at least at the time of the loss is under his control. This is not to say that the indirect effects of vice do not exact an enormous price on intimates of alcoholics and pathological gamblers or victims of drunk drivers - clearly their suffering is immense. But the direct effects of using alcohol, like those of using ketchup, are primarily sustained by the consumer himself. There are important exceptions; for instance, "second hand" smoke from cigarettes might damage the health of proximate non-smokers, and drug use by pregnant women can harm their fetuses. Nevertheless, for the most part vice is "self-regarding” behavior, to employ Mill's terminology, that does not directly damage specific others or the public at large. Controls on adult vice, then, might well fall afoul of the harm principle.

Today, Mill's harm principle presents something of a puzzle. It accords well with many of the intuitions that are widely shared in liberal democracies. ${ }^{4}$ Under the harm principle, for example, the government has no business regulating what color I paint my living room, but society does have a legitimate interest in ensuring that my children are protected against abuse and have access to education. The principle also coheres with a standard economics approach to regulation (which is unsurprising as Mill authored the text that dominated economics instruction during the latter half of the $19^{\text {th }}$ century). Government, according to this view, should intervene in activities among adults only in 
the presence of externalities. ${ }^{5}$ The costs and benefits of various actions that accrue directly to the decision makers can best be weighed by the individuals in question. Only external effects, those that are imposed on non-consenting others, provide a potential rationale for social intrusion into individual choice in well-functioning markets.

So when it comes to ruling out bans on living rooms painted yellow or on opera, we tend to side with the harm principle. At the same time, however, we might think that prohibiting convenience-store sales of heroin (to adults as well as children) is appropriate. The problem is that once we allow ourselves the heroin ban, we seem to open a door to all sorts of intrusive regulations, including bans on billiards or opera, rock and roll or yellow living rooms. As Mill asks, “...if mankind are justified in interfering with each others' liberty in things which do not concern the interests of others, on what principle is it possible consistently to exclude these cases?"

In other words, to reject the harm principle is to accept that sometimes we can interfere with the self-regarding behavior of other adults. And then consistency might require that we tolerate some tyrannous inroads upon our own liberties: ${ }^{7}$

...unless we are willing to adopt the logic of persecutors, and to say that we may persecute others because we are right, and that they must not persecute us because they are wrong, we must beware of admitting a principle of which we should resent as a gross injustice the application to ourselves.

One obvious way out of this dilemma is to employ the exceptions that Mill himself identified. Maybe engaging in vice isn't so self-regarding after all. Maybe our preferred bans implicate externalities or kids in ways that the opera ban does not. Then we can have our cake and eat it too: our preferred policies are justified through 
permissible but limited qualifications, while our continued allegiance to the harm principle means that we needn't be forced to accept that governments have the right to dictate religious practices or living room decor.

For many forms of adult vice, however, the allowable exemptions for kids and externalities can't comfortably be stretched to allow coercive government policies. Cocaine or heroin use per se, though often engendering significant harms to the user himself, involves little in the way of harms to others. As Mill's approach gives no standing for "harms to self" as a primary motivation for regulations, attempts to coerce adults away from cocaine or heroin consumption seem to violate the harm principle, even with a generous interpretation given to Mill's exemptions regarding kids and externalities. $^{8}$

But kids and externalities do not exhaust the qualifications to the harm principle. Mill noted that adults can be coerced if they are "in some state of excitement or absorption incompatible with the full use of the reflecting faculty..."9 This sort of diminished rationality seems to be characteristic of decisions involving potentially addictive substances or activities - as reflected in the frequent expressions of regret made by individuals looking back at their previous alcohol, nicotine, or cocaine careers, for example. The effects of drug taking and other addictive behaviors on the brain also support the notion that vice decisions do not involve "the full use of the reflecting faculty."

Does the potential irrationality of vice-related choices imply that a ban on heroin or cocaine can survive the application of the harm principle? Probably not. Vice was not 
unknown in Mill's day, and he was explicit on the point that private indulgence in alcohol, gambling, or prostitution, could not legitimately be suppressed under the harm principle. In other words, Mill did not view his stated qualifications as sufficiently serious to swallow his rule. Advances in neurochemistry and behavioral economics provide a stronger case than was available in Mill's time for the notion that adult vice decisions are frequently less-than-fully-rational, but the consequences of such potential "irrationality" (with which Mill was familiar) are not so assuredly detrimental that extreme compulsion becomes justified. A provisional acceptance of the irrationality of some vice-related decisions does not provide an open door for any and all varieties of coercive, paternalistic policies. Vice-related degradation of the reflecting faculty does not exempt vice controls from harm principle scrutiny.

Precisely how far can the door to vice control be opened in light of the potentially irrationality of vice-related choices? Following the hints that Mill provided, I propose a modified harm-type principle that should guide our approach to regulating vices that are associated with seemingly irrational choices. My suggestion is that desirable vice regulations should be consistent with a particular type of robustness: public policy towards addictive or vicious activities engaged in by adults should be robust with respect to departures from full rationality. That is, policies should work pretty well if everyone is completely rational, and policies should work pretty well even if a substantial number of folks are occasionally (or frequently) irrational in their vice-related choices. The first part of the "robustness principle" rules out prohibitions of most private vice; the second part rules out unfettered access to traditional vicious goods such as alcohol, tobacco, or 
cocaine. By this reckoning, high taxes, advertising restrictions, and subsidies to prevention and treatment are all potentially legitimate vice policies. Our current drug prohibitions, of course, do not meet this challenge.

Policy regimes that are consistent with the robustness principle offer a sort of compromise with the self-control problems that tend to mark vicious decision making. Vice regulations should provide some support for those who are striving to make good choices, whether those people have been generally successful or unsuccessful in the past in overcoming compulsive behavior. The trick is to provide such support without unduly inconveniencing those who, at least for the time being, can achieve the virtue of rationality (if not moderation) in dealing with temptation. ${ }^{10}$ One example of a policy that satisfies the robustness principle is a requirement for purchases of heroin, say, to be made with at least three days' notice - where the notice would be revocable by the adult wouldbe purchaser at any time during the ensuing waiting period. Rational heroin consumers, and even rational addicts, can then assure themselves of a steady supply, but those struggling with self-control issues will not be able to immediately satisfy an unforeseen craving, and can cancel an impulsive order when their decision-making faculties are controlled by their more-considered selves.

The robustness principle as applied to vice policy parallels more general regulatory approaches that have been developed in recent contributions to behavioral law and economics (see endnote 10). The "asymmetric paternalism" of Camerer et al. (2002), for instance, is a precursor in advocating policies that offer aid to less-than-rational people, while imposing at most small costs upon rational individuals. The advance 
purchase requirement for heroin suggested above is asymmetrically paternalistic;

mandatory disclosure of the risks of heroin use by sellers is another policy that meets the robustness principle and is asymmetrically paternalistic. Moderate sin taxes (see O’Donoghue and Rabin, 2003) likewise can satisfy robustness while being asymmetrically paternalistic.

The paper proceeds as follows. In section 2, I look closely at the harm principle as applied to vice regulation, and to drug policy in particular. What is perhaps most surprising is the severity of controls that are consistent with a proper Millian regard for individual liberty when externalities and protection of children are take into account, even if adult vice-related decisions are accepted as fully rational. In section 3, I briefly review some of the evidence linking addiction to disease as well as some recent work in behavioral economics; following those reviews, I relax the full rationality assumption in applying the harm principle, thereby allowing public policy to respond to the "harms to self" connected with vice. But the appropriate extent to which policy can respond to harms to self is limited, and I will examine Mill's implicit guidance as to where those limits might be. The robustness principle emerges from this exercise, in section 4. I then compare, in section 5, the robustness principle with the (unrelaxed) harm principle in terms of their implications for legitimate vice policies. The possibility for drug policy to respond to harms to adult users available under (or even required by) the robustness precept generally allows for some controls that would not be permissible under the harm principle. Nevertheless, there is much agreement between the policy implications of the 
harm and robustness principles. In particular, prohibitions aimed at adult vice consumption are inconsistent with both approaches. Section 6 offer conclusions.

\section{The Harm Principle and Vice Policy}

Simple to state, the harm principle has proven to be complex in application, an art as much as a science. Mill's concepts of self-regarding and other-regarding activities do not draw clear, unambiguous lines between different behaviors. ${ }^{11}$ Nevertheless, the harm principle certainly seems to rule out general prohibitions against adult indulgence in most vices: there would be no such thing as an illegal drug, for instance, were a straightforward interpretation of the harm principle the guiding force underlying our vice laws. Likewise, prostitution and all other forms of consensual sex involving adults would not be criminal matters. Drugs and sex could still be regulated, and perhaps even regulated quite strictly, under the standard established by the harm principle, but the private use of drugs and private exchanges for sex could not be forbidden to adults. Nor would stringent regulations on vices be justifiable under the harm principle, if those regulations approximated a total ban.

Mill provides fairly detailed guidance on the implications of his harm principle for the control of alcohol, prostitution, and gambling. Nevertheless, definitive statements (like those in the previous paragraph) about the incompatibility of an adult vice prohibition with the harm principle would not be universally accepted. For example, the harms to others that flow from drug use, along with Mill's exception for children, could be argued to provide sufficient scope to justify a heroin ban. In the remainder of section 
2, I provide a more extensive justification for my proposed interpretation of the ramifications that the harm principle holds for drug policy.

\subsection{Kids}

Children are widely regarded as being fit subjects for prohibitions against consuming or producing vice, at least in the absence of parental supervision. There are many tricky issues, such as identifying an appropriate minimum drinking age or age of consent for sexual activities, but the conviction that the law can and should attempt to shield children from unbridled vice is all but universally accepted. The difficulty for the harm principle comes when regulations undertaken to further the interest of protecting children from vice involve collateral restrictions on adults.

If there are regulations short of prohibition for adults that can effectively and costefficiently control the harm to children, then these regulations would be preferable to a complete ban. ${ }^{12}$ Even if such efficacious controls are not available, a prohibition might be unwise, if the ban does a poor job at reducing the use by children or reduces that use while imposing other, possibly more significant, harms.

Maybe authorized adult access to recreational drugs, even if regulated, opens channels that would not otherwise exist for making the drugs available to kids, and with this availability comes significant harm. Drug policy expert John Kaplan thought so, based in part on the experience with alcohol and tobacco, as he indicated in his influential 1988 article that argued against the legalization of hard drugs: “...legal access for adults makes a drug de facto available to the young., ${ }^{\prime 3}$ There are different degrees of 
availability, however. It is one thing for a drug to be available to older teenagers who invest enormous resources in tracking it down. It is something else entirely if every junior high school cafeteria table has its own supplier.

Even if the legal availability of a drug to adults implies some availability to youths, the force of that implication in recommending a prohibition for adults depends on the relative availability of the drug to the young under a regime of prohibition. It cannot be taken for granted that drugs that are legal but regulated for adults will be more available to kids than drugs that are prohibited. The access that teens have to a prohibited drug depends upon many factors, including the extent of enforcement of the prohibition and the fashionableness of the drug. Certainly various illicit drugs are readily available to inner city youths; indeed, employment opportunities in the distribution chain of such drugs also appear to be widely available to kids in the inner city. Many American teenagers find it easier to acquire marijuana, a prohibited drug, than alcohol or cigarettes, substances widely and legally available to adults, though prohibited for kids. ${ }^{14}$ (Nor do kids appear to be commonly employed in the chain of distribution for alcohol.) The vast majority of American high school seniors, inner-city or not, can expeditiously procure pot. For each of the last thirty years, between 82 and 91 percent of twelfth-graders surveyed as part of the Monitoring the Future project have indicated that marijuana is either fairly easy or very easy to obtain. ${ }^{15}$ Further, the harmfulness of drug use by children is not simply a function of the prevalence of that use. Prohibition might, for instance, lead to less drug use (by both adults and kids) than in a legal, regulated market, but the 
potential to overdose might be higher under prohibition because the strength of a dose would not be standardized.

Nevertheless, significant leakage of a drug to children from a legal adult market combined with substantial harm from that leakage provides one rationale for a drug prohibition, even for committed Millians. Note the use of the qualifier "significant," which indicates the extent to which application of the harm principle is a matter of judgment. Given the evidence concerning marijuana (and other drug) availability and the employment of young children in some sectors of the illegal drug trade, I generally do not think that any marginal increase in availability to kids through leakage from a legal adult market would be significant enough to justify, in itself, an adult prohibition of a recreational drug - but others might legitimately disagree. One difficulty of making categorical pronouncements here is that drug legalization would undoubtedly hold different consequences for different kids. Those youths who live in neighborhoods where drugs are already rife would probably see a decrease in drug availability through legalization and regulation - for these kids, drugs are essentially unregulated under the prohibition regime. For kids who live in neighborhoods without widespread drug markets, however, it is possible, even likely, that some forms of legalization would lead to increased availability. ${ }^{16}$

Another kid-related issue that holds implications for the regulation of drugs is that adults who are addicted to hard drugs by and large do not make good parents. That is, perhaps a legal adult market for a drug does not increase the use of the drug by kids, or does increase use but with a lower level of overall harm to kids. Nevertheless, if such 
availability leads to child neglect on the part of parents, then adult drug use still involves "harm to others" that might provide a second kid-based rationale for a prohibition.

In On Liberty, Mill addressed this type of harm to others - the neglect of duties, including parental duties, stemming from indulgence in a drug or another vice. If such indulgence would necessarily or with a very significant probability lead to such neglect, then a prohibition might be in order: ${ }^{17}$

...when a person disables himself, by conduct purely self-regarding, from the performance of some definite duty incumbent on him to the public, he is guilty of a social offence. No person ought to be punished simply for being drunk; but a soldier or policeman should be punished for being drunk on duty. Whenever, in short, there is a definite damage, or a definite risk of damage, either to an individual or to the public, the case is taken out of the province of liberty, and placed in that of morality or law.

But if the risk of damage to others is not so immediate or immanent, then punishment should be targeted at the infliction of damage, and not at the behavior that "caused" the imposition of harm. A man whose profligacy leads to the destitution of his family can be "justly punished," whether his spending went to alcohol or "the most prudent investment" - but the punishment is "for the breach of duty to his family or creditors, not for the extravagance. ${ }^{\prime 18}$

While child neglect is a bad thing, therefore, it does not serve as a Millian rationale for a drug prohibition, unless any consumption of the drug as assuredly leads to child neglect as being drunk on duty leads to severely diminished performance by a police officer. Someone who had once neglected a duty through his indulgence in a vice, however, could be prohibited from future indulgence, as Mill noted, without the prohibition constituting an unacceptable limitation upon individual liberty. ${ }^{19}$ A parent 
who became neglectful or abusive under the influence of drugs or by a fixation on finding and using drugs could face a drug prohibition targeted personally at him or her. ${ }^{20}$

Recall that Mill restricts the applicability of the harm principle to "human beings in the maturity of their faculties." Perhaps when it comes to making choices about drugs, and particularly those choices that are made while under the influence of drugs, adults share with children the feature of not being "in the maturity of their faculties." When a heroin addict wakes up in the morning, is his decision to go out in search of a fix the decision of a fully reflective agent? Perhaps not - we will look more fully into the rationality of vice-related choices in section 3 . An easier case, though, arises when the would-be purchaser is intoxicated. Mill makes it clear that coercion is permissible in this situation: restraining someone who is already drunk from having another round or from driving home is not a prima facie violation of the individual's liberty, as the person is "in some state of excitement or absorption incompatible with the full use of the reflecting faculty...,21

\subsection{The Ubiquity of Externalities}

The notion that drug taking or some other vice might justly be prohibited if the activity involves "definite damage, or a definite risk of damage, either to an individual or to the public" is the source of another argument that attempts to reconcile the harm principle with drug prohibition. The idea is to point to harm to others from drug use, harm that is sufficiently likely and significant that an individual's drug taking could not be characterized as self-regarding activity. For such an approach to succeed in justifying 
prohibition under Mill's standards, the external harms from drug use would have to approximate those brought about by a drunk police officer - the potential (though quite uncertain) harms of drug-induced neglect of familial duties would not be sufficient. Social scientist James Q. Wilson adopts a version of the "significant harms-to-others" approach:

John Stuart Mill, the father of modern libertarians, argued that people can only restrict the freedom of another for their self-protection, and society can exert power over its members against their will in order to prevent harm to others. I think that the harm to others from drug legalization will be greater than the harm - and it is a great harm - that now exists from keeping these drugs illegal. ${ }^{22}$

For Wilson, an individual's drug use apparently involves "definite damage, or a definite risk of damage," to the public, like that of a drunken cop. Wilson is not alone: "Today, the harm principle is being used increasingly by conservatives who justify laws against prostitution, pornography, public drinking, drugs, and loitering, as well as regulation of homosexual and heterosexual conduct, on the basis of harm to others. ${ }^{23}$

Just about any activity that harms the person engaging in it also harms those who are attached to that person, as Mill recognizes: "I fully admit that the mischief which a person does to himself may seriously affect, both through their sympathies and their interests, those nearly connected with him and, in a minor degree, society at large."${ }^{\prime 24}$ One family member's addiction to alcohol, drugs, or gambling frequently throws a household into misery. At the societal level, insurance involves the pooling of risks, so a person who takes actions that make it more likely he or she will collect insurance payments harms the other members of the risk pool. ${ }^{25}$ Similarly, public subsidies to medical care imply that 
the ill health of many drug addicts imposes a cost upon the rest of society. Pathological gambling can increase the rate of bankruptcy and drive up borrowing costs for everyone.

We have previously seen that Mill would permit the punishment of those who violate family and societal duties through their vicious activity, or through any other cause. But the harm principle would not countenance prohibiting an activity simply because a small percentage of those who engage in it will subsequently violate such duties. Further, minimizing the potential to require publicly subsidized health care is not an obligation that society can legitimately impose upon individuals, without opening the way to regulation of the minutest aspects of our activity, from what we eat to how much we exercise to what time we go to bed to how we spend our leisure hours. ${ }^{26}$ Nevertheless, it would probably not be an invasion of individual liberty to require private insurance for individuals who choose to engage in exceptionally risky ventures, those activities that involve a very significant risk of claiming societal resources. Mountain climbers, intent upon scaling a peak that frequently has required expensive rescues of previous would-be climbers, might have to post a bond in advance to pay for the rescue services that they, too, might require.

When the risk of damage to the interests of others is sufficiently large, as in the case of the drunken police officer, society can try to use the law to prevent harm. Without an ample risk of harm to others, however, the criminal law is an inappropriate tool for regulating vice. How certain is "harm to others" from occasional indulgence in a vice? Typically, rather uncertain - most drug users and most gamblers indulge in ways that are not particularly problematic for even their close friends and relations. Even for cocaine 
and crack cocaine, drugs that are strongly reinforcing, only a small percentage of people less than ten percent, and perhaps as little as one percent - who use these substances develop into habitual users. ${ }^{27}$ In the US, where the vast majority of adults have gambled, about 1.2 percent can be classified as pathological gamblers. ${ }^{28}$ While external costs from addiction are high, then, these costs are insufficiently certain to arise from experimental or occasional indulgence to justify criminalization of drugs or gambling.

But with regard to the merely contingent or, as it may be called, constructive injury which a person causes to society by conduct which neither violates any specific duty to the public, nor occasions perceptible hurt to any assignable individual except himself, the inconvenience is one which society can afford to bear, for the sake of the greater good of human freedom. ${ }^{29}$

Again, to justify the use of coercion, Mill's explication of the harm principle requires that conduct breach a specific public duty or directly and perceptibly harm some "assignable" individual. Would-be prohibitionists cannot simply assert that they are harmed by the conduct of others: there must be some perceptible harm:

There are many who consider as an injury to themselves any conduct which they have a distaste for, and resent it as an outrage to their feelings; as a religious bigot, when charged with disregarding the religious feelings of others, has been known to retort that they disregard his feelings by persisting in their abominable worship or creed. But there is no parity between the feeling of a person for his own opinion and the feeling of another who is offended at his holding it, no more than between the desire of a thief to take a purse and the desire of the right owner to keep it. ${ }^{30}$

Mill indicates that in the case of alcohol, prohibition is a violation of the harm principle. In particular, he attacks the "Maine Laws," state-level prohibitions on alcohol that were current in the mid-19th Century United States and were in some danger of 
being exported to England. ${ }^{31}$ This suggests that Mill would also view the harm principle as filtering out prohibitions on sales of other drugs to adults. A more careful examination of the external harms of drug use might nonetheless be called for before we can apply the harm principle with confidence to drug regulation.

\subsection{External Costs of Drug Use}

Drug researcher Mark Kleiman offers one potential accounting of "harms to others" associated with drug use: dereliction of duty; crime; nuisance; health damage; drain on common resources; risk-spreading and cross subsidy effects; leading others to use drugs (in epidemiological fashion); and notional damage. ${ }^{32}$ (Notional damage is the possibility that some people are made unhappy or disgusted simply by knowledge of others' drug use..$^{33}$ )

Note that Kleiman's list of potential external effects of drug use consists of those effects associated with drug use per se, independent of the policy regime. Many of the costs commonly associated with drugs, however, are primarily artifacts of the existing regulatory structure, including the drive-by shootings and the bulk of the fatal overdoses. Under the influence of some drugs - alcohol is the preeminent example, but cocaine and PCP would also qualify - people might be more likely to commit violent crimes, though even this tendency involves the social setting and many factors beyond the drug's

chemical properties. ${ }^{34}$ (Those under the influence of nicotine, opiates, or marijuana do not appear to be increasingly predisposed towards violence, although in the past, these drugs, too, have been thought to be violence-inducing.) With the particularly notable exception 
of alcohol, however, the perceived relationship between drug use and crime is primarily a side effect of prohibition.

Consider Kleiman's first three external costs, dereliction of duty, crime, and public nuisance. We have already seen that the harm principle does not prevent police officers and soldiers from being punished for being drunk on duty, because their inebriation presents a definite risk of damage to the public. More generally, dereliction of duty (such as failure to provide for children) could be punished, whatever the cause. But the potential for drug taking to lead to this outcome is not sufficiently direct and certain to justify making drugs illegal. Likewise, the crime that is engendered by some types of drug consumption - violence by drunks, for instance - is not sufficiently direct and certain to stand as a basis for outlawing drugs. The external harm that arises from creating a public nuisance, like the harms from dereliction of duty or drug-induced crime, could provide a reason to punish those who create public nuisances. Again, however, the public nuisance associated with some drug use is insufficiently direct and certain to justify drug prohibitions (though some less stringent regulations aimed at minimizing nuisance would not unduly restrain the liberty of drug consumers.) If a person had once been violent under the influence of alcohol or drugs, however, then a prohibition specific to that person would be appropriate, for some period of time.

When the health of others is damaged by an individual's drug taking, as by second-hand smoke, then legal controls potentially are warranted. Whether the actual damage to health caused by second hand smoke (or similar remote health effects from other drug use) is sufficiently direct or certain, given current evidence, is less clear; 
certainly the extent of exposure matters, and would make intervention more justified in those places where non-smokers are involuntarily subjected to frequent exposure of relatively high concentrations. ${ }^{35}$ Where such effects exist, regulations are not inconsistent with the harm principle - though the regulations should not be more restrictive of individual choice to use drugs than is necessary to prevent the negative external health consequences. ${ }^{36}$

Kleiman's remaining types of external costs (drains on common resources, riskspreading and cross subsidy effects, leading others to use drugs, or "notional" damage) do not rise to the Millian level to justify prohibition: such costs generally do not breach a public duty, nor constitute "perceptible hurt to any assignable individual."37

So, the interpretation offered here of Mill's approach does not provide all that much scope for legislation overriding the personal liberty of adults to engage in vice even when accounting for the kids and externality exceptions. While some strict controls are consistent with the harm principle, channels for legal adult consumption of recreational drugs must remain open, from Mill's point of view. Table 1 offers a summary of the implications of Mill's harm principle for drug policy. 
Table 1: John Stuart Mill as Drug Czar: A Capsule Summary of Drug Policy Screened Through the Harm Principle ${ }^{38}$

Prohibitions of manufacture or possession: These would not be allowed for any drug that offered even the remotest hope of benefitting (or failing to damage) someone. ${ }^{39}$ Individuals who had previously harmed others while intoxicated, however, could be subject to a specific prohibition. Kids could be prohibited from using drugs. Further, those "doped up" at the time of attempted purchase could justly be refused service, just as bartenders can refuse to serve intoxicated customers, on the grounds that such patrons are "in some state of excitement or absorption incompatible with the full use of the reflecting faculty..."

Prohibitions on sales: If sellers are "indispensably required" for legitimate use of the drug, then prohibitions upon sales are unallowable infringements on liberty. ${ }^{41}$ The Maine laws or national alcohol Prohibition in the US, which outlawed sales but not purchases or consumption of alcohol, were inconsistent with individual liberty - Mill believed that in the case of alcohol legal sales were a near necessity for consumption. But in general, prohibitions on sales are a close call. Buying and selling is a public act, and hence not a species of self-regarding conduct. Trade can be prohibited without violating individual liberty, as long as there readily exist alternative channels through which consumers could acquire their drugs.

Regulations (short of prohibition) on sale: Many controls are allowable and potentially desirable, including requirements of warning labels, registration of sales for the purpose of crime control, sanitary or worker safety regulations, licensing of sellers, and opening hours restrictions. Limiting the number of sellers simply as a means to discourage consumption (as opposed to being an aid in enforcing other regulations) is an infringement upon the liberty of potential purchasers, however. ${ }^{42}$

Prohibitions or regulation of advertising: Such restrictions on sellers, who have a pecuniary interest in intemperance, may be justified. But private individuals can freely advise or induce others to use drugs. ${ }^{43}$

Special taxation: This is not justified if the goal of the taxation is to reduce consumption. ${ }^{44}$ If the goal is the collection of necessary government revenue, however, then drugs could and should be taxed, up to the point of maximum revenue collection. ${ }^{45}$

Prescription-only regimes: To make drugs available only by prescription generally cannot be countenanced, as a prescription regime places too great a burden upon those who have legitimate, including recreational, uses for the drugs. ${ }^{46}$ Some "non-recreational" drugs involve externalities that might justify a prescription regime, however. In particular, antibiotic use harms others by contributing to the build-up of resistant strains 
of pathogens; so, antibiotics could be subject to a prescription regime as a means of countering socially excessive use.

License requirements for legal purchase or use: If the conditions for qualifying for a license are that the buyer or user indicate he or she understands the risks involved in consumption, or conditions that might aid in the enforcement of other legitimate regulations, then such a licensing system would not fall afoul of the harm principle. But a licensing system for adult buyers could not be adopted simply as a means of reducing consumption.

Regulating intoxicated behavior: Prohibiting an intoxicated person from engaging in certain types of activity (such as driving under the influence) is not a violation of individual liberty, if the behavior presents a definite risk of harm to others. Public intoxication might justifiably be regulated - Mill notes that many acts that are not harmful in themselves can nevertheless be restricted in public manifestations. ${ }^{47}$ Private intoxication, however, cannot be prohibited.

\section{Addiction, Disease, and the "Excitement" Exception}

Accepting the harm principle, then, makes it hard or impossible to defend bans on adult vice, such as our current drug prohibitions. But why accept the harm principle?

Despite the general accord of the harm principle with the tenets of liberal democracies, Mill's approach has never attracted anything like unanimous consent. You don't have to look too hard to find denunciations of Mill's harm principle among vice policy experts.

John Kaplan again:

No nation in the world follows [Mill's] rule regarding self-harming conduct, and the rule is probably unworkable in a complex, industrial society - particularly one that is a welfare state. Mill's principle, moreover, seems singularly inappropriate when it is applied to a habitforming, psychoactive drug that alters the user's perspective as to postponement of gratification and his desire for the drug itself. ${ }^{48}$

Or this, from James Bakalar and Lester Grinspoon: 
When Mill wrote On Liberty, absolute freedom of trade still seemed defensible; the disease concept of drug abuse was only an opinion, not an institution; and the medical profession and medical science were relatively feeble. We will never return to the social and intellectual conditions that made possible Mill's opposition to all drug laws. ${ }^{49}$

Earlier in the same book from which the previous quote is drawn, Bakalar and Grinspoon suggested that today people "are much less inclined than Mill to treat drug use as the free, rational act of an autonomous person."

The notion that habitual drug use is irrational or that addiction is a disease offers an exception to the harm principle, by making the addict out to be someone not in the maturity of his faculties, or without the full use of the reflecting mechanism. But is addiction a disease?

\subsection{A Disease View of Addiction}

Neurobiological factors play a key role in much drug use. The reward structure of our brains (and of animal brains) provides a motive towards behavior that is generally beneficial for the individual (or his or her genes), activities such as eating, drinking, and sex. One main channel for reward in humans is dopamine neurotransmission within a part of the brain known as the medial forebrain bundle. ${ }^{51}$ Addictive drugs, including alcohol and nicotine, have differing and complex effects on brain chemistry, but they all stimulate the dopamine reward mechanisms - despite being unconnected to the beneficial behavior that the reward system developed to motivate. In all likelihood, it is this stimulation that makes drug use so reinforcing. "[A]ddiction results when the reward system of the brain 
is hijacked by chemical substances that played no role in its evolution." 52 In other words, drug addiction can be viewed as a disease, an unhealthy physical condition.

Much of the evidence concerning the effect of drugs on the brain, and thereby on behavior, is drawn from studies on animals. Addiction does not seem to occur to nonhuman animals in the wild. ${ }^{53}$ In experimental settings, however, animals can be induced to press a bar repeatedly for a reward of a drug like cocaine, to the exclusion of all else. (They can be induced similarly to push a bar when pushing results in a direct electronic stimulus to the reward area of their brain.) "[A] monkey will self-administer [cocaine] to exhaustion - not eating, not drinking, and ignoring opportunities for sexual activity. Eventually, such a monkey will die taking cocaine - of starvation or dehydration or sudden heart stoppage caused by the drug excess in the body." 54

The "short-term benefit, long-term cost" nature of drug use also is reflected in brain chemistry. Acute administration of a drug produces the brain reward noted above. Repeated drug use, however, tends to cause "homeostatic" adjustments in the brain. The excessive dopamine presence created by the drug use leads the brain's own reward circuitry to become degraded in various ways. One result, apparently, is tolerance and withdrawal symptoms. More of the drug is needed to achieve the same hedonic effect, and the absence of the drug leads to unpleasant feelings, anhedonia. These longer term effects on brain chemistry from drug use, of course, can themselves reinforce the desire to use the drug.

This brief description of the neurobiology of drug use is hopelessly oversimplified. The precise mechanisms through which drugs affect the brain are 
multifarious, and to some extent remain unknown. For example, the central role played in addiction and relapse behavior by cravings induced by environmental cues suggests that drugs influence the part of our brain that forecasts how much we will enjoy some activity, and not just the brain region that provides the reward during consumption. ${ }^{55}$ Withinsession effects can be different from both acute and chronic impacts; for instance, an initial dose of cocaine might lead to sensitization, where the closely following dose has a larger, not a smaller impact, than the first dose ${ }^{56}$ Nevertheless, the general brain reward mechanism seems to be a key element in reactions to most addictive drugs. ${ }^{57}$ Amazingly, behavioral addictions such as pathological gambling involve brain chemistry in ways that are not dissimilar from those of drug addiction. ${ }^{58}$

The disease view of addiction lends itself to understanding drug use as an act initiated by a patient, a victim of disease, to medicate his affliction. Some people have a brain reward system that is relatively underdeveloped, so the "artificial" stimulation of drugs or gambling might be needed for their brains to function "normally." This view is particularly compelling in the case of opiate addiction because there are some naturally produced opiate-like substances, endorphins (from "endogenous morphines"), in the brain. Someone with "too few" endorphins might rationally treat his condition by ingesting morphine, heroin, or some other opioid. For such a person, narcotics use could compensate for his inborn deficiency, just as diabetics rely on insulin injections to make up for their own natural shortcoming. By these lights, both junkies and diabetics use drugs to become "normal." ${ }^{59}$ Users of non-opiate drugs likewise might be compensating for a neurobiological condition, a substandard dopamine neurtotransmission system. This 
condition has been termed "reward deficiency syndrome." ${ }^{60}$ For those individuals with reward deficiency syndrome, drug use might not be a free choice, much less a rational choice.

The degradation of the brain's own reward circuitry that follows heavy drug use implies that even people who cannot initially be characterized as exhibiting reward deficiency syndrome end up suffering from a form of that condition. They start out as "normal," but they experiment with a drug, and they really enjoy it. They naturally seek to repeat that pleasurable experience, by taking the drug again - and again, and again. Homeostatic adjustments within their brain then begin to kick in, so that their "baseline" level of pleasure is degraded. Eventually, taking the drug still provides a pleasure boost, but because their baseline has shifted, the drug only makes them feel normal, the way they felt without any stimulus prior to their addiction. Potentially addictive drugs or activities are a trap: a known trap but nonetheless a subtle one. ${ }^{61}$

\subsection{Dynamic Inconsistency and Addiction}

Recent advances in behavioral economics also call into question the extent to which adult vice-related choices are optimal, even from the point of view of the decision maker. The short-term benefit, long-term cost nature of much drug use, for example, might lead to impulsive decisions eventually followed by regret. Rational individuals might discount delayed costs differently as time passes - that is, rational behavior does not require "time consistency." Someone whose preferences display time consistency would be able to plan future behavior today (contingent, perhaps, on such things as future 
prices), and would stick by that plan in the future. Someone with time inconsistent preferences, alternatively, might develop an optimal plan today, but decide not to follow the plan tomorrow. What the person now thinks will be his best choice one year from now, will, when the year has passed, no longer appear to be his best choice - even if neither improved information nor additional options become available.

There is substantial evidence that individual choices are not time consistent. ${ }^{62}$ Further, departures from dynamic consistency are rather systematic, not random, and apply widely. People tend to be more impatient when making decisions concerning the present and near future than when they make decisions concerning the more distant future. Would you rather have $\$ 1000$ today or $\$ 1075$ in one week? Many people would prefer the immediate $\$ 1000$. What if, instead, the choice were between $\$ 1000$ to be received precisely 227 days from today, or $\$ 1075$ to be received precisely 234 days from today? In this case, many people would choose (today) to wait the extra week (in 227 day's time) for the additional $\$ 75$. People are typically less willing to postpone gains in the present than they are when making decisions about the future. Note that, when 227 days go by, and people are then asked to choose between an immediate $\$ 1000$ or $\$ 1075$ in one week, these same people will presumably revert to preferring the immediate $\$ 1000$ - they would not want to follow the plan they viewed as optimal 227 days earlier. This is the sense in which their choices do not display time consistency.

Regret is one of the markers of dynamic inconsistency, and one that appears to be particularly connected with decisions that involve current pleasures paired with future costs. Many people regret overspending or saving too little money, for instance. (The 
source of the word "addict" is the Latin word "addictus," which in ancient Rome referred to those imprudent or unfortunate souls whose excessive debts led to their being enslaved to their creditors under judicial order.) Such people tend to view their previous decisions as short-sighted, which is not to say that these people will become more forward-looking in the future. It is as if we are two people, a prudent Dr. Jekyll and an intemperate Mr. Hyde, but it is our capricious, imprudent self who is making our current decisions as to whether or not to have a beer, play a video game, or pick up smoking. Looking back as Dr. Jekyll, we regret Mr. Hyde's previous choices.

That dynamic inconsistency is at least part of the issue with addiction is lent credence by the fact that many addicts seem to engage in a contest for self-control, a struggle between the desire for the drug and the desire to quit. ${ }^{63}$ Addicts frequently describe their predicament in precisely these terms, as if they were two separate people battling for dominance of the decision-making power. Sometimes people invest in various sorts of self-control devices, designed to lower the payoff from future indulgence - investments that are hard to square with the notion that vicious choices are fully rational and time consistent. ${ }^{64}$

Dynamic inconsistency could greatly alter the appropriate policy towards drugs or other potentially addictive goods, even if it is accepted that users are rational. ${ }^{65}$ As individuals themselves are comprised of time-specific entities who have different preferences, "harm to others" could be construed to include "harm to your future self" harm that you will not fully take into account, because your future self will have different preferences than your current view of that person's preferences. "Internalities" is the term 
applied to these "internal externalities." ${ }^{96}$ Personal rules that help us to precommit to low consumption of a potentially addictive good or otherwise fortify our self-control are one common method adopted to give our future selves their due.

Public policies, like personal policies, might want to respond to the internalities that arise when a person's "current" self imposes costs on his or her "future" self; that is, the government might be in a position to help Dr. Jekyll control Mr. Hyde. ${ }^{67}$ Taxes are one lever by which government can reduce consumption of targeted goods. In the case of cigarettes, to fully induce current consumers to take into account the costs they impose on their otherwise under-represented future selves, it has been estimated that an additional tax of $\$ 1$ per pack of cigarettes might be justified. ${ }^{68}$ If the measure of happiness is a person's long-run preferences (i.e., Dr. Jekyll's preferences), such a tax can contribute to a smoker's happiness - a startling revision of the standard economics notion that a consumer cannot be made better off when the price rises for a good she already purchases. $^{69}$

\section{The Robustness Principle}

Recall that John Stuart Mill's harm principle, as interpreted in Table 1, is consistent with extensive regulation of addictive substances and activities. About the only types of regulation that the harm principle surely rules out are prohibition of possession or use backed by criminal penalties, and making substances available by prescription only. The nature of addiction does not altogether negate the force of the harm principle: decisions concerning potentially addictive substances and activities generally cannot be 
said to be insane or irrational. At the same time, however, addiction shares many features of disease, so choices by addicts legitimately can be classified as being made in a state that is not consistent "with the full use of the reflecting faculty." Social coercion of such decisions, then, does not run afoul of the harm principle.

Most vice-related decisions appear to be both rational and self-regarding. Many others are not fully rational, or implicate dynamic inconsistency. Mill's harm principle would allow social intervention with respect to the irrational decisions, but generally it is not possible to know which choices are rational, and which are irrational. It isn't even clear when someone's consumption of a drug or an activity crosses the line from "occasional" or "controlled" to "habitual" or "compulsive."

Once we accept that many choices with respect to potentially addictive goods are not fully rational - or at least that there is a strong case to be made that such choices are not fully rational - are we then left with nothing, no principle that could limit the most extreme coercive measures from being applied to vice choices? No, and Mill himself provides the way, in his discussion of commodities that can be used both for beneficial purposes and for the purpose of committing crimes. With respect to poisons or similar dual-use articles, Mill endorses regulations that aid in deterring the nefarious use, while not being too burdensome upon those consumers with innocent intent. "Such regulations would in general be no material impediment to obtaining the article, but a very considerable one to making an improper use of it without detection." ${ }^{70}$ We saw a similar balancing act applied to Mill's condemnation of prescription-only systems: the requirement of having to first obtain permission from a licensed physician is too onerous 
a burden to impose upon drug consumers, even though such a requirement would help insulate some problematic users from drug use.

That some adult vice-related consumption is less-than-rational, and that we cannot easily distinguish rational from irrational choice with respect to vice, suggests that we forge a compromise when constructing public policy - as Mill argued with respect to the sale of dangerous goods. Vice regulations should provide some support for those who are struggling with self-control in their decision-making. The provision of such support should not impose substantial costs upon those whose vice-related decisions are marked by rationality.

This leads us to the robustness principle, as described in the introduction. Public policy towards potentially addictive activities should be robust with respect to departures from full rationality. Vice policy for adults should hold up pretty well if everyone is always fully rational, and it should work well, too, even if some or many vice-related choices are irrational. We require this robustness precisely because we cannot easily ascertain how much vice is rational, nor distinguish the rational component from that which flows from a degradation of the reflecting faculties.

The robustness principle, then, has been fashioned by combining the harm principle with (1) the notion that vice-related choices are particularly likely to fall short of full rationality and (2) the Millian idea that regulations aimed at harmful activities should not impose large costs upon their non-harmful counterparts. In the next section, I will look at the implications that the robustness principle holds for drug policy. 


\section{Drug Regulation Under the Robustness Principle}

The main difference between the robustness principle and the harm principle with respect to their ramifications for vice policy is that the robustness principle allows for regulations to be aimed directly at reducing harms to vice consumers themselves. Indeed, the robustness principle might require such regulations, on the grounds that their absence could result in a regulatory regime that is woefully ineffective in the face of widespread vice-related self-control problems. To aid the comparison between the harm and robustness principles, the discussion here will be restricted to drug policy.

Consider again Table 1. The strictest controls - most particularly, prohibition of drug possession - are as incompatible with the robustness principle as they are with the harm principle, because such strict controls fare poorly when applied to rational drug consumers. The differences between the principles are made manifest in those circumstances where Mill specifically rules out policies that are intended to restrict drug consumption. These areas include regulations upon sellers; taxation; and licensing requirements for legal purchase. In all of these policy realms, Mill would permit controls that serve other legitimate ends, even if those controls have the collateral effect of making it harder for people to consume drugs. He would not accept these measures, however, if they were aimed directly at reducing drug use.

The robustness principle, alternatively, would permit the adoption of some controls designed solely to reduce adult drug use. Limiting the number of sellers (or their hours of operation) to render it somewhat inconvenient to procure drugs impulsively, therefore, is permissible under the robustness principle - as long as the restrictions do not 
become significantly burdensome for those whose drug consumption choices are fully considered. Similarly, buyer licensing (or some other hurdle to drug availability) would not run afoul of the robustness principle, even if the licensing had no other purpose than to reduce harms to drug users themselves by rendering procurement more arduous. Sin taxes, for Mill, are constrained to be no higher than the revenue-maximizing level. For robustness purposes, such taxes are limited by the burden that they place upon rational consumers. This limit could exceed or fall short of the revenue-maximizing exaction.

For further illustration, let's look at the possibilities for regulating heroin under the robustness principle. Heroin use can be immensely dangerous; nevertheless, the use of heroin involves little direct harm to others. (That is, doped-up heroin fiends do not typically go on crime sprees induced by heroin's pharmacological properties. Heroin is a narcotic, a drug that tends to induce listlessness, not violence, though individual responses to heroin vary widely. ${ }^{71}$ ) How strict can the heroin regulatory regime be made without violating the robustness principle?

First, kids could be prohibited from purchasing or possessing heroin, and anyone could be prohibited from selling or otherwise transferring heroin to underage consumers. But if this prohibition is no more effective than current prohibitions on kid purchases of alcohol and cigarettes, then too many kids will be using heroin. ${ }^{72}$ So, as under the harm principle, we must invoke collateral regulations on adults to reduce the porousness of the ban on youth access to heroin. In particular, adults could face a quantity restriction on how much heroin they can purchase (each month, say). The purpose of this quantity restriction is not to reduce adult consumption, but rather, to prevent a lone rogue adult 
from supplying heroin to an entire high school. That is, quantity restrictions for adults can be adopted to help police the black market for youth (or ineligible adult) access.

Similarly, purchases could be required to be arranged in advance, or sales could be made only through mail-order, so that the heroin equivalent of teenagers waiting outside the convenience store to pay an adult to buy them a six-pack of beer would be foreclosed.

The robustness principle (unlike the harm principle) allows us to go beyond those quantity limits and advance-purchase requirements that help to shield teens from adult drug access. Further quantity limitations - that is, quotas more restrictive than those that would "optimally" preclude youth access - could be adopted, as a way of restricting adult usage. These quotas could not be so tight, however, as to render it difficult for a rational adult addict to maintain himself in his addiction: quotas that significantly restrict adult addicts would run afoul of the robustness principle, for being too costly upon rational consumers. Similarly, using the robustness standard, there is further scope for advance purchase requirements - that is, requirements that go beyond what is needed to police the black market. Even prolonged advance purchase mandates do not impose significant burdens upon considered use. A month-in-advance purchase regulation would probably meet the robustness principle, even if it offered no more of a barrier to black market acquisition than a 24-hour requirement.

To implement the quantity restrictions, there must be a method to identify consumers and to keep track of their purchases. Adults would need some sort of credit card-like identification that can record their purchases and check the quantity of purchases against a database. Do all adults automatically qualify for such a card, which is 
essentially a license to purchase limited amounts of heroin, or are there special conditions that must be met before someone is deemed eligible for a drug license?

In the terminology of Mark Kleiman, the issue is whether the authorization to purchase comes in the form of a "negative license" or a "positive license." license is one that is automatically available to all adults; however, someone who creates a public nuisance, drives a car recklessly, or commits another crime under the influence of heroin, or who diverts the heroin to youths, or in any way imposes harms on others through heroin use or distribution, could then have his or her heroin license revoked. In other words, with negative licensing, socially destructive behavior connected with heroin use would result in a prohibition specific to the wrongdoer - a policy that, as we have seen, also is consistent with Mill's application of his harm principle.

A positive licensing scheme is one where adults must meet other qualifications before they can acquire the credentials to purchase heroin. (Drivers' licenses include a positive element, in that applicants for such licenses generally must pass road tests, written tests on the traffic law, and vision tests.) In the case of heroin, adults might have to pass an exam indicating that they understand the dangers of its use. As with negative licenses, positive licenses could be revoked for misbehavior, in the same manner in which drivers' licenses are revoked. A positive licensing scheme involving a test of knowledge of the dangers of drugs is, I believe, consistent with the robustness and harm principles: as Mill notes with respect to a requirement to label poisons, "the buyer cannot wish not to know that the thing that he possesses has poisonous qualities." ${ }^{, 74}$ But a sane adult who understands the risk of heroin cannot be prevented from using it, as "liberty consists in 
doing what one desires," and "...no one but the person himself can judge of the sufficiency of the motive which may prompt him to incur the risk...."75 So under the robustness principle, adults could face a positive licensing scheme, where to receive the right to purchase limited quantities of heroin they would have to pass a test concerning the risks of heroin use and perhaps the laws surrounding heroin use, and their license would be subject to revocation if they harmed others through their heroin-related activity. $^{76}$

One advantage of a licensing scheme for heroin is that private responses could help keep the costs of heroin misuse low. ${ }^{77}$ Employees in sensitive positions might face the absence of a heroin license as a job requirement. Insurance companies might offer lower rates to policy holders who opt to forego a heroin license. There is even precedent of sorts - Thomas De Quincey, nineteenth century author of Confessions of an English Opium Eater, expressed great dismay at the unwillingness of life insurers to grant him a policy because of his opium habit. ${ }^{78}$

Abiding by the robustness principle does not imply that private sellers need be countenanced. Heroin could be distributed only through state stores, for instance, and as noted, an advance purchase requirement could be imposed. Advertising could be banned, and the heroin could be subject to a substantial (though not prohibitive) tax. ${ }^{79}$ It might be sensible not to make taxes so high that the incentive to evade the taxes spawns a flourishing black market. Presumably the advantages of receiving heroin of a known purity would make black market heroin a very imperfect substitute for the legal supply. 
As a result, heroin taxes could probably be quite significant, as excise taxes often are for alcohol or tobacco, without generating massive underground sales. ${ }^{80}$

License holders could be given the option to precommit not to purchase any heroin for a period of time, say, one week or even one day, in a binding way. That is, the government could provide a mechanism to help people voluntarily manage the selfcontrol problem that is an obstacle for many people with drugs or alcohol or cigarettes. In moments when their cravings are not intense, individuals might choose to limit their possibilities for future (legal) consumption for a few days, even if they are unwilling to forestall those possibilities indefinitely by relinquishing their license. (Such opt-outs are not uncommon in the regulation of gambling.) Or, they could choose a license that permits them some heroin, but an amount less than the legal quantity limit. Taxes could be repositioned from being ad valorem or specific to consisting of a single, annual license fee. ${ }^{81}$

With the robustness principle as the basis of drug policy, therefore, a very restrictive regime over heroin could be implemented. Kids could be forbidden from acquiring drugs, and adults could be required to be licensed before purchasing limited amounts of heroin. Commercial sales and advertising could be prohibited, and significant sin taxes could be imposed. But adults who wanted to acquire heroin, and whose past use had not resulted in any wrongful conduct, would have a safe and legal means to do so.

Alternatively, an extremely liberal policy towards addictive goods such as heroin would not be countenanced under the robustness principle. (This is opposed to the situation with the harm principle, under which laissez faire would be a consistent policy.) 
The requirement that public policy lead to tolerable results in the face of significant departures from rationality suggests the necessity of aiding actual and potential addicts with their self-control. Licensing, taxation, and advance purchase requirements for some addictive goods, then, might be near-requirements imposed by the robustness principle, and not just consistent with it. Information provision about addiction treatment options (such as now occurs in the form of phone numbers for Gamblers Anonymous printed on lottery tickets) and even publicly subsidized access to treatment are other policies that might be necessary to reduce the harms suffered by less-than-rational users.

\section{Conclusions}

The chief alternative to framing the discussion of vice policy in terms of stated principles is to rely upon expedience. In the US in recent decades, that approach has generally meant that perceived new drug threats are met by an enhanced version of the current prohibition: more severe penalties, additions to the list of controlled substances, a widening of the prohibition to encompass precursors, paraphernalia, or devices to confound drug tests. With expedience as our guide, the problems that arise under prohibition transmute into arguments for a more intense or broader prohibition. ${ }^{82}$

While expedience seems to be the current driver of much drug policy, at some point, prohibition was a choice made from a wider set of available policies. (That point in the US was 1914 for opiates and cocaine and 1937 for marijuana.) The principle underlying this choice (and underlying current defenses of prohibition) seems to be that drugs are tempting but harmful. Of course, the syllogism "drugs are bad, therefore they 
must be prohibited" is as logically unsound as it has turned out to be destructive in practice. Nevertheless, prohibition proponents are correct that some drugs are highly problematic. The challenge posed by John Kaplan - "Probably the central problem with the solution [to our drug predicament] of legalization is that it ignores basic pharmacology. There is such a thing as a dangerous drug..." ${ }^{\Perp 3}$ - cannot simply be dismissed. Resistance to the generally appealing harm principle tends to come in the form of Mill's near-dismissal (in terms of public policy) of the problem of dangerous drugs and the harms that such drugs bring upon their adult users.

The robustness principle is not similarly dismissive. It accepts that some drugs are dangerous, and that public policy should aim, in part, to reduce the damage that drugs wreak upon their users. But it does so while also recognizing limits to the harm that the policies themselves can impose upon rational drug consumers. Prohibition of drug possession is not compatible with the robustness principle, though many strict controls are compatible. What the robustness principle demonstrates is that acceptance of those strict controls does not imply that the only governing principle is the logic of persecutors; drugs can be strictly controlled without opening the door to prohibitions upon opera, or billiards - or drugs. 


\section{References}

Bakalar, James B., and Lester Grinspoon, Drug Control in a Free Society, Cambridge: Cambridge University Press, 1984.

Baldino, Rachel Green, Welcome to Methadonia: A Social Worker's Candid Account of Life in a Methadone Clinic. Harrisburg, PA: White Hat Communications, 2000.

Becker, Gary S., and Kevin M. Murphy, "A Theory of Rational Addiction.” Journal of Political Economy 96: 675-700, 1988.

Becker, Gary S., Michael Grossman and Kevin M. Murphy, "The Economic Theory of Illegal Goods: The Case of Drugs.” National Bureau of Economic Research Working Paper \#10976, December 2004.

Bernheim, B. Douglas and Antonio Rangel, "Addiction and Cue-conditioned Cognitive Processes." American Economic Review 94(5): 1558-1590, December 2004.

Blum, Kenneth, John G. Cull, Eric R. Braverman, and David E. Comings, "Reward Deficiency Syndrome.” American Scientist, March-April, 1996.

Bonnie, Richard J., “Addiction and Responsibility.” Social Research 68(3): 813-834, Fall 2001.

Boyum, David, "The Distributive Politics of Drug Policy," Drug Policy Analysis Bulletin, no. 4, February 1998. Available at fas.org/drugs/issue4.htm\#politics (visited June 16, 2005).

Camerer, Colin, Samuel Issacharoff, George Loewenstein, Ted O'Donoghue, and Matthew Rabin, "Regulation for Conservatives: Behavioral Economics and the Case for 'Asymmetric Paternalism.'” May 2002.

Carnwath, Tom, and Ian Smith, Heroin Century. London: Routledge, 2002.

CASA. "National Survey of American Attitudes on Substance Abuse IX: Teen Dating Practices and Sexual Activity." The National Center on Addiction and Substance Abuse at Columbia University, August 2004.

CASA. "National Survey of American Attitudes on Substance Abuse VII: Teens, Parents and Siblings." The National Center on Addiction and Substance Abuse at Columbia University, August 2002. 
Cook, P.J., and M. J. Moore, "Economic Perspectives on Reducing Alcohol-Related Violence.” In S. E. Martin, ed, Alcohol and Interpersonal Violence: Fostering Multidisciplinary Prespectives, National Institute on Alcohol Abuse and Alcoholism Research Monograph No. 24, NIH Publication Number 93-3496, Bethesda, MD, 1993.

Dworkin, Gerald, "Paternalism" In Richard A. Wasserstrom, ed., Morality and the Law, Belmont, California: Wadsworth Publishing Company, Inc., 1971.

Eldredge, Dirk Chase, Ending the War on Drugs. A Solution for America. Bridgehampton, New York: Bridge Works Publishing Company, 1998.

Elster, Jon, Strong Feelings. Cambridge: MIT Press, 1999.

Feinberg, Joel, Offense to Others. Volume 2 in The Moral Limits of the Criminal Law. Oxford: Oxford University Press, 1985.

Feinberg, Joel, Harm to Self. Volume 3 in The Moral Limits of the Criminal Law. Oxford: Oxford University Press, 1986.

Gambling Impact and Behavior Study. Final Report to the National Gambling Impact Study Commission. National Opinion Research Center, March 18, 1999. Available at http://www.norc.uchicago.edu/new/gamble.htm (visited July 27, 2005).

Gardner, Eliot L., "The Neurobiology and Genetics of Addiction: Implications of the 'Reward Deficiency Syndrome' for Therapeutic Strategies in Chemical Dependency." In Jon Elster, ed., Addiction: Entries and Exits, New York: Russell Sage Foundation, 1999.

Goldstein, Avram, Addiction: From Biology to Drug Policy, second edition. Oxford: Oxford University Press, 2001.

Gruber, Jonathan, and Botond Köszegi, "Is Addiction 'Rational'? Theory and Evidence." National Bureau of Economic Research Working Paper 7507, January 2000.

Gruber, Jonathan, and Sendhil Mullainathan, "Do Cigarette Taxes Make Smokers Happier?” NBER Working Paper \#8872, April 2002.

Haasen, Christian, and Michael Krausz, "Myths Versus Evidence with Respect to Cocaine and Crack: Learning From the US Experience." European Addiction Research 7 (4): 159-160, December 2001.

Harcourt, Bernard E., "Criminal Law: The Collapse of the Harm Principle.” Journal of Criminal Law and Criminology 90: 109-194, Fall, 1999.

Hart, H. L. A., Law, Liberty, and Morality. Stanford: Stanford University Press, 1963. 
Hawkins, Gordon and Franklin E. Zimring, Pornography in a Free Society. Cambridge: Cambridge University Press, 1988.

Herrnstein, R.J., George Loewenstein, Drazen Prelec, and William Vaughan, Jr., "Utility Maximization and Melioration: Internalities in Individual Choice." Journal of Behavioral Decision Making 6: 179-185, 1993.

Kaplan, John, “Taking Drugs Seriously.” The Public Interest, No. 92, pp. 32-50, Summer 1988. Reprinted in Schaler (1998, pp. 92-108).

Kleiman, Mark, Against Excess: Drug Policy for Results, New York: Basic Books, 1992.

Loewenstein, George, “Out of Control: Visceral Influences on Behavior.” Organizational Behavior and Human Decision Processes 65(3): 272-92, 1996.

Loewenstein, George, Ted O’Donoghue, and Matthew Rabin, "Projection Bias in Predicting Future Utility." Quarterly Journal of Economics 118(4): 1209-1248, November 2003.

Loewenstein, George, and Richard H. Thaler, "Intertemporal Choice." Journal of Economic Perspectives 3(4): 181-193, Autumn 1989.

MacCoun, R. J., and P. Reuter, Drug War Heresies: Learning from Other Vices, Times, and Places. Cambridge: Cambridge University Press, 2001.

Markowitz, Sara, "Alcohol, Drugs and Violent Crime." International Review of Law and Economics 25: 20-44, 2005.

Masson, David, editor, The Collected Writings of Thomas De Quincey. Volume III. London: A. \& C. Black, 1897.

Mill, John Stuart, On Liberty. Edited by Elizabeth Rapaport, Indianapolis/Cambridge: Hackett Publishing Company, 1978.

Monitoring the Future, 2004. Available at www.monitoringthefuture.org. Tables and figures for 2004 available at http://www.monitoringthefuture.org/data/data.html (visited July 27, 2005).

Morgan John P., and Lynn Zimmer, "The Social Pharmacology of Smokeable Cocaine: Not All It's Cracked Up To Be." Chapter 7, pp. 131-170, in Crack in America: Demon Drugs and Social Justice, Craig Reinarman and Harry G. Levine, editors, Berkeley: University of California Press, 1997. 
National Survey on Drug Use and Health. Available at http://oas.samhsa.gov/nsduh.htm (visited July 27, 2005).

O'Donoghue, Ted and Matthew Rabin, "Studying Optimal Paternalism, Illustrated by a Model of Sin Taxes." American Economic Review 93(2): 186-191, May 2003.

O'Donoghue, Ted, and Matthew Rabin, “Addiction and Self-Control." In Jon Elster, ed., Addiction: Entries and Exits, New York: Russell Sage Foundation, 1999.

Packer, Herbert L., The Limits of the Criminal Sanction. Stanford: Stanford University Press, 1968.

Pope, Thaddeus Mason, "Balancing Public Health Against Individual Liberty: The Ethics of Smoking Regulations." University of Pittsburgh Law Review 61, Winter 2000.

Posner, Richard A., Sex and Reason. Cambridge, Massachusetts: Harvard University Press, 1992.

Robson, Philip, Forbidden Drugs, second edition. Oxford: Oxford University Press, 1999.

Schaler, Jeffrey A., ed., Drugs. Should We Legalize, Decriminalize or Deregulate? Amherst, NY: Prometheus Books, 1998.

Schultz, Wolfram, "Getting Formal with Dopamine and Reward." Neuron 36: 241-263, October 10, 2002.

Smith, Steven D., "The Hollowness of the Harm Principle." University of San Diego School of Law, Legal Studies Research Paper No. 05-07, September 2004.

Sullum, Jacob. Saying Yes. In Defense of Drug Use. New York: Jeremy P. Tarcher, 2003.

Thaler, Richard H., and Cass R. Sunstein, "Libertarian Paternalism." American Economic Review 93(2): 175-179, May 2003.

Waal, Helge, and Jørg Mørland, “Addiction as Impeded Rationality.” In Jon Elster, ed., Addiction: Entries and Exits, New York: Russell Sage Foundation, 1999.

Wilson, James Q., “Legalizing Drugs Makes Matters Worse.” Slate, September 1, 2000. Available at http://slate.msn.com/id/88934; visited July 18, 2005. 
Endnotes

1. “Officials Rail Against Vice, Ban Billiards," Chicago Tribune, October 3, 2002, p. 6.

2. Mill (1978, p. 9).

3. Mill (1978, p. 9).

4. The word "liberal" here is employed in the $19^{\text {th }}$ Century (Millian) sense of being focused on individual liberties. Smith (2004), while criticizing the uses to which the harm principle has been put, nevertheless notes its seeming simplicity and intuitive appeal as contributing to its popularity.

5. As with harm to others, the existence of externalities, under this approach, provides a necessary but not sufficient condition for government intervention. Monopoly power might present another rationale for regulation. Indeed, any departure from first-best competitive conditions, in theory, could generate an efficiency rationale for government intervention, and the government might also adopt regulations for distributional, as opposed to efficiency, concerns.

6. Mill (1978, p. 84). The "cases" that Mill specifically refers to are the limitation of public faith to that of Roman Catholicism and a legal prohibition against marriage for members of the clergy.

7. Mill (1978, p. 84).

8. Harms to self can be targeted as a secondary effect of policies that serve other ends; for example, special taxes on cocaine are permissible from Mill's perspective, as long as the primary motivation is to raise government revenue. See Table 1, infra.

9. Mill (1978, p. 95).

10. A similar approach is taken by many authors within the behavioral law and economics tradition. See, e.g., O’Donoghue and Rabin (2003), Thaler and Sunstein (2003), Camerer et al. (2002), and Loewenstein, O’Donoghue, and Rabin (2003).

11. "To make a satisfactory distinction between these two sorts of conduct requires the kind of practical, historically informed, and commonsensical, although unrigorous, analysis that Mill undertook in chapter 4 ["Of the Limits to the Authority of Society Over the Individual”] of On Liberty.” Posner (1992, p. 438).

12. Here I am invoking what Pope (2000, p. 431), quoting Dworkin (1988, p. 126), terms "the principle of the least restrictive alternative." Mill (1978, p. 94) subscribes to this principle, too: "...leaving people to themselves is always better, caeteris paribus, than controlling them...." 
13. Kaplan (1998 [1988], p. 98). Hawkins and Zimring (1988, p. 201) make a similar point with respect to pornography: "[P]ornography cannot be made freely available in mainstream retail channels for adults and be made scarce for children."

14. Results of a survey of 1000 teens ( 12 to 17 year olds) published in 2002 indicated that 34 percent found marijuana easier to purchase than either cigarettes or beer, with smaller percentages choosing the legal goods as the easiest to buy; see CASA (2002). The 2004 edition of the yearly survey found that cigarettes were easier to buy than marijuana, which was easier to buy than beer; CASA (2004). The annual Monitoring the Future surveys consistently show that marijuana is less readily available to teens than alcohol or cigarettes, however.

15. See Table 13, "Trends in Availability of Drugs as Perceived by Twelfth Graders," in Monitoring the Future (2004).

16. Boyum (1998) argues that such distributional asymmetry is one of the factors underlying the seeming political unpopularity of the legalization of currently illicit drugs. See also Becker, Grossman, and Murphy (2004).

17. Mill (1978, pp. 79-80).

18. Mill (1978, p. 79).

19. Mill (1978, pp. 96-7).

20. Temporary prohibitions specific to an individual are already employed to some extent, in the case of both illegal drugs and alcohol. In the US, for example, many individuals on probation or on pre-trial release have their freedom conditioned on remaining drug or alcohol free.

21. Mill (1978, p. 95).

22. Wilson (2000).

23. Harcourt (1999, p. 139).

24. Mill (1978, p. 79).

25. This claim assumes that the risk has not been appropriately priced in the insurance premium.

26. As Mill (1978, p. 80) wrote, "If grown persons are to be punished for not taking proper care of themselves, I would rather it were for their own sake than under pretense of preventing them from impairing their capacity of rendering to society benefits which society does not pretend it has the right to exact." The underpinnings of our commitment to socially-subsidized access to health care might also be inconsistent with a system that 
selectively withholds such care from those who have made "unapproved" decisions; for instance, would subsidized emergency-room treatment be made unavailable to drivers who injure themselves in accidents that occur when they are speeding?

27. According to the National Survey on Drug Use and Health, in 2003 more than 34 million Americans (12 and older) had used cocaine at least once in their lives. Cocaine treatment admissions in 2003 came to nearly a quarter million people, about 0.72 percent of the lifetime users. See Haasen and Krausz (2001, p. 160) for the contention that cocaine addiction affects a subset of less than 5 or 10 percent of cocaine users. Eldredge (1998, p. 11), states that "Fewer than 1 percent of those who try cocaine become daily users," a contention based on data he discusses on page 2 .

28. Gambling Impact and Behavior Study (1999).

29. Mill (1978, p. 80). But also see the discussion of "garrison thresholds" in Feinberg (1986, pp. 21-23). Feinberg's four volume The Moral Limits of the Criminal Law provides a painstaking analysis of the harm principle and related concepts. Other important examinations of the Millian harm concept include Hart (1963) and Packer (1968).

30. Mill (1978, pp. 81-2).

31. Mill (1978, pp. 86, 94-5, 99).

32. Kleiman (1992, Chapter 3).

33. On notional damage, see Feinberg's (1985, pp. 60-71) discussion of the "bare knowledge problem."

34. On alcohol and violence, see Cook and Moore (1993). Sullum (2003, pp. 205-8) indicates that there is scant evidence for a link between PCP and violent behavior. Morgan and Zimmer (1997, p. 137) argue that "there is no evidence that cocaine causes generally nonviolent people to behave violently." Markowitz (2005) includes a good discussion of substance use, violence, and causality.

35. Controversy over the dangers of second-hand smoke was reignited with the 2003 publication of a study in the British Medical Journal that indicated no link between lung cancer or heart disease and exposure to second-hand smoke. See "Claim that Passive Smoking Does No Harm Lights Up Tobacco Row,” by Sarah Boseley, The Guardian, May 16, 2003, p. 1 (international edition).

36. Again, I am invoking "the principle of the least restrictive alternative"; see Pope (2000, p. 431), quoting Dworkin (1988, p. 126).

37. Mill (1978, p. 80). 
38. In the United States, "Drug Czar" is the informal sobriquet for the person who heads the Office of National Drug Control Policy.

39. See Mill (1978, p. 95).

40. Mill (1978, p. 95).

41. Mill (1978, p. 99).

42. Mill (1978, pp. 96, 100).

43. Mill (1978, pp. 97-8). In the US, a broad advertising ban for a legal product might be construed as being inconsistent with First Amendment protection of the freedom of speech.

44. Mill (1978, p. 95).

45. Mill (1978, p. 100). Strictly speaking, Mill's injunction that goods like alcohol should be highly taxed is consistent with but not a consequence of his harm principle - it stems from other considerations of desirable public policy. Mill's general support for free trade, too, is not a consequence of harm principle reasoning.

46. Mill (1978, p. 96) is explicit on this point.

47. Mill (1978, p. 97).

48. Kaplan (1998 [1988], p. 95).

49. Bakalar and Grinspoon (1984, p. 69). Incidentally, in On Liberty, Mill does not advocate "absolute freedom of trade" on the grounds that trade restrictions violate individual liberty, nor does he oppose "all drug laws."

50. Bakalar and Grinspoon (1984, p. 4). See also H. L. A. Hart (1963, pp. 32-34), who notes "a general decline [since Mill's time] in the belief that individuals know their own interests best," and "an increased awareness of a great range of factors which diminish the significance to be attached to an apparently free choice or to consent."

51. In this section, I rely primarily upon Gardner (1999) and Goldstein (2001).

52. Elster (1999, p. 53).

53. Bakalar and Grinspoon (1984, p. 41).

54. Goldstein (2001, p. 59).

55. See the discussion in Bernheim and Rangel (2004) and Schultz (2002). 
56. See, for example, Goldstein (2001, p. 183).

57. That there is some overlap in the brain reaction to many drugs is suggested by the phenomenon known as cross-priming - a small dose of one drug tends to produce a craving in an addict for another substance, his usual drug of choice. Despite crosspriming, however, drugs are not perfect substitutes for one another. A heroin addict or an alcoholic will not fully be satisfied by the nicotine in a cigarette, even though all three drugs tend to enhance dopamine neurotransmission. Gardner (1999, p. 74) and Elster (1999, p. 83).

58. See, e.g., Gardner (1999, pp. 78f), and Waal and Mørland (1999, p. 132). Recently it has been reported that some patients taking dopamine agonists to treat Parkinson's disease develop an unexpected side effect: a new-found compulsion to gamble. See "Parkinson's Treatment Linked to Compulsive Gambling," Scientific American.com, July 12,2005 , available at http://www.sciam.com/article.cfm?chanID=sa003\&articleID=0008C23C-CEE1-12D2-8E E183414B7F0000 (visited on July 18, 2005).

59. Robson (1999, p. 200). Also, see the discussion in Goldstein (2001, p. 101) and Baldino (2000, p. 154).

60. See Blum et al. (1996).

61. Even initial drug use may in part depend on such factors as biological predispositions to risk-taking behavior; see the discussion of "Onset" in Bonnie (2001, pp. 820-1).

62. See, e.g., Loewenstein and Thaler (1989) and O'Donoghue and Rabin (2001).

63. Bakalar and Grinspoon (1984, p. 46) refer to the "paradox of habit," where a person views her actions, simultaneously, as being her own and not her own.

64. Though the discussion here has focused on time inconsistency, there are alternative approaches within the field of behavioral economics that involve different types of departures from full rationality. For instance, people might be subject to "projection bias," where they overestimate how similar their future preferences will be to their current preferences; see Loewenstein, O'Donoghue, and Rabin (2003). Or, their decisions might be excessively controlled by "visceral factors," in a manner that they neither fully anticipate nor appreciate in hindsight; see Loewenstein (1996).

65. This is the argument of Gruber and Köszegi (2000). Becker and Murphy (1988) present a model that captures many elements of addiction, within a rational, time consistent framework.

66. The term "internalities" derives from Herrnstein et al. (1993). 
67. On internalities, see, e.g., O'Donoghue and Rabin (1999).

68. Gruber and Köszegi (2000). The additional tax is relative to the amounts commonly prevailing in the US at the end of the 1990s.

69. Gruber and Mullainathan (2002).

70. Mill (1978, p. 96).

71. When heroin is illegal, however, the expense of a heroin habit (combined with the difficulties addicts have in holding regular employment) leads many addicts to engage in crime to raise money for the drug. On the heterogeneity of responses to heroin and other opiates, see Chapter 5 in Carnwath and Smith (2002).

72. It might reasonably be argued that "even one kid using heroin is too many;" however, a regime of prohibition (for both kids and adults) itself results in a good deal of kid use of heroin, as is evident in both Europe and the US. So the fact that the kid prohibition would be imperfect under a legal regime for adult heroin use is insufficient in itself to deny heroin to adults.

73. Kleiman (1992, pp. 98-101).

74. Mill (1978, p. 96).

75. Mill (1978, p. 95).

76. Incidentally, heroin maintenance programs, in which existing addicts qualify to receive supplies legally, are a type of positive licensing scheme. Maintenance is a quite strict licensing regime, as the "test" for receiving a license requires, not knowledge of the risks of heroin, but establishing a verifiable addiction.

77. Kleiman (1991, pp. 99-100).

78. De Quincey fulminates against his insurance problems in the 1856 revision of his Confessions; see Masson (1897, pp. 426-9).

79. A ban on advertising of a legal good might not satisfy the demands of the First Amendment in the US, of course, but the point here is to indicate the contours of a drug policy consistent with the robustness principle alone.

80. Legal access to opioids would likely induce a shift away from heroin use towards less potent drugs such as opium itself; the introduction of opioid bans frequently has instigated a shift in the other direction, towards heroin use, just as alcohol Prohibition in the US instigated a shift from beer to more potent spirits.

81. See O’Donoghue and Rabin (2003). 
82. MacCoun and Reuter (2001, p. 133) make a similar point about arguments for the prohibition of gambling.

83. Kaplan (1998 [1988], p. 93). 